\title{
Investigating the Factors of Contraception use among Female Sex Workers
}

\author{
Yekti Satriyandari(i), Yushe Quasimah, Enny Fitriahadi*(D), Endang Koni Suryaningsih (D) \\ Department of Midwifery, Faculty of Health Science, Aisyiyah University Yogyakarta, Yogyakarta, Indonesia
}

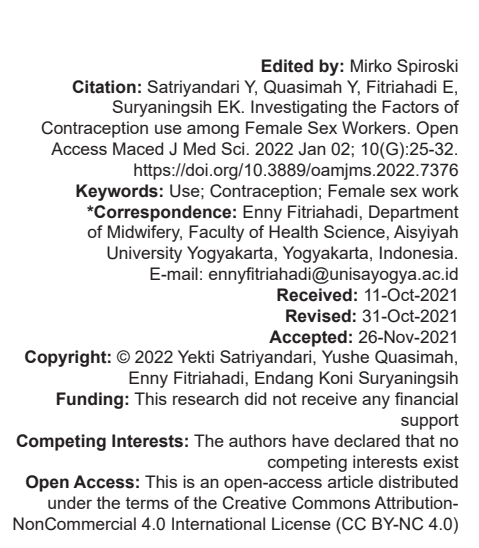

\section{Abstract}

BACKGROUND: Prostitution is a social problem because prostitution harms the safety, tranquility and prosperity physical, spiritual, and social of the common life, it becomes real when connected with the transmission of venereal diseases, the views of several religions and traditional traditions of the tribes in Indonesia. One of the consequences of unhealthy sexual activity is emergence of sexually transmitted diseases. To do the PMS, it has developed various methods of contraception that can be used by the public at large.

AIM: The study aims to determine the factors of contraceptive use in commercial sex workers in Yogyakarta Indonesia.

RESULTS: This research employed a quantitative approach with cross-sectional design. Respondents involved were 30 commercial sex workers. The results showed that most respondents used condom contraceptives as many as 21 people $(70.0 \%)$, most respondent have an age of $18-40$ years as many as 24 people $(80.0 \%)$, most respondent have elementary education as many as 16 people (53.3\%) and most of the respondents had a high income of 25 people $(83.3 \%)$.

IMPLICATION FOR PRACTICE: It's hope that in the coming year educational institutions can complete references to books on concepts, especially about community midwifery care to support student research in completing research.

\section{Introduction}

In South Africa, at least -third of sex workers are HIV positive at 24 years of age, and the infection rate is up to $80 \%$ among older women. Furthermore, HIV transmission between female sex workers (FSWs) and their clients' accounts for about 6-20\% of all heterosexual transmission in South Africa. Resolve these barriers through better service delivery to linking sex workers to early antiretroviral treatment important if global goals are ambitious to end The HIV epidemic by 2030 will be reached [1]. The use of long-acting reversible contraceptive (LARCs) among FSWs is low in many countries, six particularly in sub-Saharan Africa, where prevalence is reported as less than $5 \%$ in most studies 1,7 . Use of IUDs among FSWs varies considerably between regions, with higher levels in parts of Latin America and Asia [2].

In Asia and Africa, the prevalence of abortion among FSWs ranges between 22 and $86 \%$. A study among FSWs in Zambia showed that women who reported a lifetime pregnancy also had a history of unplanned pregnancy, depicting a large unmet need for contraception among FSWs [3]. Estimating the actual number of FSWs globally, available data indicate that in sub-Saharan Africa about $0.7-4.3 \%$ of women exchange sex for money or goods. In Uganda, 3.3\% of women aged 15 and above were estimated to be FSWs in Kampala's capital city. Since FSWs are at an increased risk of both unwanted pregnancy and sexually transmitted diseases (STDs), some have resorted to dual protection (simultaneous use of both condoms and female-controlled modern nonbarrier methods). Approximately, $67 \%$ of participants reported using a non-barrier method for contraception, but fewer than $20 \%$ of participants reported using both condoms and a non-barrier method [3].

FSWs are someone who sells her services for sexual intercourse. Prostitution in Indonesia has become widespread. Symptoms of prostitution are expected to continue to increase. The practice of child prostitution in Indonesia is very worrying, so it must be handled seriously and involving all parties. A commercial sex worker is someone who sells his services to have sexual relations for money. In Indonesia, commercial sex workers as prostitutes are often referred to as harlots or sundels, which shows that the harlot's behavior is very bad, despicable, and becomes people's enemy [4].

Known from a social life perspective, not all people can accept the position of FSWs in the community. Indirectly, sex workers who are also human in interacting with others experience discrimination in making friends. These sex workers are shunned in social interactions. One of the unhealthy sexual activity consequences is STDs emergence [5]. The use of 
commercial sex workers who do not use contraceptives can cause and disseminate venereal and skin diseases. The most common diseases are Syphilis and Gonorrhoe, HIVIAIDS, and unwanted pregnancies. The disease, if untreated perfectly, can cause physical and spiritual disabilities in yourself and offspring [6]. Evidence indicates that correct and consistent condom use may be complicated, especially with steady and emotional partners, or through coercion by other clients who refuse to use condoms by promising to pay more or using violence [3]. Twenty-seven percent of adolescent FSWs had never used any modern contraceptive. Condoms (69\%) and oral contraceptives (38\%) were most commonly reported, and less than 3\% had ever relied on an intrauterine device (IUDs). We found low rates of dual protection (34\%) and consistent condom use [7]. The prevalence of HIV was $12.1 \%(95 \%$ confidence interval [Cl],] 9.7-14.9). One-quarter of women reported currently using a LARC, including 204 implant users (22.6\%) and 13 IUD users (1.6\%). 54.6\% the women reported using condoms consistently with all partners, with 235 (26.3\%) doing so alongside another method [2]. The higher rate of condom use compared to hormonal contraceptives, particularly among younger FSWs, may reflect their knowledge of condoms' dual role in pregnancy and STI/HIV prevention. The low rates of condom use by intimate partners point to the need for dual protection from STIs/HIV and unwanted pregnancies [8].

The government's role in providing information sources on contraceptive use is urgently needed by community, especially to ward off false information (rumors) about contraception. Personally, it can be seen how someone wants to use contraception. This is mainly about the economic situation of contraceptive users. With the fees charged for each type of contraception, people feel burdened [9]. In general, contraceptives used by FSWs are condoms. This contraceptive can have multiple functions in addition to preventing pregnancy; it also serves to prevent the transmission of HIVIAIDS. However, in practice, FSWs sometimes use condoms when serving consumers. This is according to previous research [10] which states that condom contraceptives use in FSWs in Sukosari, sub district Bawen, district Semarang $65.6 \%$ sometimes use condoms. Although there are many publications about FSWs use contraceptive but few see from the factors that feed the use of contraceptives. Based on data from the Gedongtengen Public Health Center in 2017, there were 324 sexually transmitted sex workers in Kembang market area, 28 of whom were positively infected with syphilis. Whereas data in 2018, there were 423 FSWs who had STIs, from HIV epidemiological data in Indonesia, STI cases in Indonesia were reported that, in 2016 , syphilis was $12.19 \%$, cases of urethral discharge were $13.12 \%$, the vaginal discharge was $72.84 \%$ and genital ulcers were $1.83 \%$. The number of HIVIAIDS and syphilis cases in Yogyakarta in 2016, HIV 59.01\%, AIDS $23.07 \%$ Aids and syphilis $17.90 \%$.
The use of contraceptives is very necessary, because it is also a protection against STIs in addition to preventing pregnancy. Commercial sex workers also combine condom use with additional contraception as a double precaution because condom use has a high failure rate. They choose contraception such as taking birth control pills, injections of progestins, and injections of combination. Most commercial sex workers have difficulty in determining the choice of contraception. This is not only due to the limited number of methods available, but also because of their ignorance of the requirements and safety of the contraceptive method. The choice of contraceptive is influenced by several factors that are considered in the choice of contraception. The factors that influence the choice of contraception are effectiveness, safety, frequency of use, side effects and willingness and ability to use contraception, also based on the cost and role of religion and culture regarding contraception, other factors are frequency of sexual intercourse, ease of getting pregnant again. Again, the side effects to lactation and future effects of contraception.

According to [11], there are factors that influence contraception use, that is, Predisposing factors (age, education, knowledge, number of children), possible factors (availability of contraceptives), and driving factors (support from husbands, support from health workers). Higher a person's education level, the better one's knowledge of contraceptives and the more rational in using contraceptives. Elsewhere, a lack of targeted services, expensive travel costs, health care service hours and sex work stigma have been identified as barriers to health and social services among FSWs and could potentially restrict access to reproductive health services and impact levels of pregnancy and contraceptive usage among women in our sample [8] he role of a midwife in contraceptive services is as a counselor and facilitator. In carrying out this role, the steps that must be taken are establishing good communication with clients, assessing the client's needs and conditions, providing information about the choice of contraceptive methods that can be used by clients, helping them to make choices, explaining in full about the contraceptive methods that have been used. Selected clients and refer clients when necessary (Health Ministry, Republic of Indonesia, 2014). This study aimed at exploring the factors of contraception use among commercial sex workers.

\section{Methods}

This study used a descriptive quantitative research approach with a cross-sectional design approach. Respondents involved in this study were 38 sex workers in Yogyakarta, Indonesia. The respondents were recruited based on their willingness to participate 
in the study and their status as sex workers. Meanwhile, those who excluded in this study do not meet the criteria mentioned earlier. Overall, eight respondents were excluded from this study, since they did not meet the criteria. Thus, 30 respondents involved actively in the data collection process. Data were collected through interview with the respondents on their contraception use, age, education, and income. We also used a questionnaire consisting of several questions in the objective form regarding the choice of contraceptives, age, education, and income for commercial sex workers. These processes were done within 15-30 min on each respondent. No 1014/KEP-UNISA/IV/2019.

\section{Results}

Based on cross-tabulation table of respondents' characteristics by contraceptives use in commercial sex workers, it can be seen that respondents characteristics aged 18-40 years are 21 respondents (70.0\%). In educational characteristics, it seen that respondents elementary school mostly used condom contraceptives, about 16 respondents (53.3\%). The respondents' characteristics with income levels showed that respondents with high income levels mostly used condom contraceptives as many as 21 respondents (70\%).

\section{Discussion}

\section{Puse contraception}

The analysis indicates that $76.7 \%$ of respondents used condom contraception, $23.3 \%$ of respondents used contraceptive pills, and no respondents who used injectable contraceptives, IUDs, implants and sterility. Condoms are the only effective method for preventing STIs and HIVIAIDS in transgender women who are sexually active and have a high risk of transmitting STIs and HIVIAIDS. FSWs have many sexual partners. Condom function is to prevent the entry of semen and germs into the intercourse and also to prevent men from contracting disease germs from body fluids and those in women's intercourse. Condoms are not porous so that men and women will be protected and are not susceptible to disease germs from their partners [12]. Condoms can have multiple functions, namely, in addition to preventing pregnancy, they also function to prevent transmission of HIVIAIDS. Most commercial sex workers have difficulty determining the use of contraceptives. It is not only because of the limited available methods, but also because of their ignorance of the contraceptive method's requirements and safety [13].

Previous research shows that $77.5 \%$ of FSWs explain to customers about the prevention of sexually transmitted infections using condoms and if condoms are unavailable at work, $90 \%$ of FSWs take the initiative to provide their own. This study indicates that the behavior of FSWs in providing information on STI prevention using condoms and the initiation of providing condoms is in the category of good behavior [14]. The availability of condoms can facilitate a person to use a condom during sexual intercourse. The use of condoms depends on condoms provision, the ease with which they are available and the affordable prices for condoms. The easier it is to find condoms, and the more affordable they are, the more likely it is used. Previous research by Budiono [15] streveale dates that consistency in using condoms by sex workers or their clients will minimize the risk of STIs, if sex workers have a supportive perception of the ability to have safe sex, viz. using condoms consistently (always using condoms) during sexual intercourse, sex workers or their customers will be protected from sexually transmitted infections. The results showed that from 56 respondents; it was found that commercial sex workers who chose to use contraceptive pills were $3.57 \%$, injections were $3.57 \%$, implants were $3.57 \%$, IUDs were $0 \%$, injections combined with condoms were $33.92 \%$ and pills combined with condoms of $55.37 \%$. It is concluded that the majority of commercial sex workers choose to use injectable contraceptives and condom.

In line with the previous research, the prostitutes use 3 months birth control injection to prevent

Table 1: Cross-tabulation of respondents' characteristics with contraceptives use on commercial sex workers (FSWs)

\begin{tabular}{|c|c|c|c|c|c|c|c|c|c|c|c|c|c|c|}
\hline \multirow[t]{2}{*}{ Characteristics } & \multicolumn{14}{|l|}{ Use } \\
\hline & Condom & $\%$ & Pill & $\%$ & Injection & $\%$ & IUD & $\%$ & Implant & $\%$ & Sterile & $\%$ & Total & $\%$ \\
\hline \multicolumn{15}{|l|}{ Age } \\
\hline $18-40$ years & 21 & 70 & 3 & 10.0 & 0 & 0 & 0 & 0 & 0 & 0 & 0 & 0 & 24 & 80.0 \\
\hline $41-60$ years & 2 & 6,7 & 4 & 13.3 & 0 & 0 & 0 & 0 & 0 & 0 & 0 & 0 & 6 & 20.0 \\
\hline Total & 23 & 76.7 & 7 & 23.3 & 0 & 0 & 0 & 0 & 0 & 0 & 0 & 0 & 30 & 100 \\
\hline \multicolumn{15}{|l|}{ Education } \\
\hline Elementary school & 16 & 53.3 & 0 & 0 & 0 & 0 & 0 & 0 & 0 & 0 & 0 & 0 & 16 & 53.3 \\
\hline Junior high school & 5 & 16.7 & 7 & 23.3 & 0 & 0 & 0 & 0 & 0 & 0 & 0 & 0 & 12 & 40.0 \\
\hline Senior high school & 2 & 6,7 & 0 & 0 & 0 & 0 & 0 & 0 & 0 & 0 & 0 & 0 & 2 & 6,7 \\
\hline Diploma & 0 & 0 & 0 & 0 & 0 & 0 & 0 & 0 & 0 & 0 & 0 & 0 & 0 & 0 \\
\hline Bachelor & 0 & 0 & 0 & 0 & 0 & 0 & 0 & 0 & 0 & 0 & 0 & 0 & 0 & 0 \\
\hline Total & 23 & 76.7 & 7 & 23.3 & 0 & 0 & 0 & 0 & 0 & 0 & 0 & 0 & 30 & 100 \\
\hline \multicolumn{15}{|l|}{ Income } \\
\hline High & 21 & 70 & 4 & 13.3 & 0 & 0 & 0 & 0 & 0 & 0 & 0 & 0 & 25 & 83.3 \\
\hline Low & 2 & 6,7 & 3 & 10.0 & 0 & 0 & 0 & 0 & 0 & 0 & 0 & 0 & 5 & 16.7 \\
\hline Total & 23 & 76.7 & 7 & 23.3 & 0 & 0 & 0 & 0 & 0 & 0 & 0 & 0 & 30 & 100 \\
\hline
\end{tabular}


pregnancy [16]. The lifestyle of free sex that exists in commercial sex workers is at risk of contracting sexually transmitted infections such as gonorrhea, trichomoniasis, genital herpes, HIV infection and syphilis. Therefore, the use of condoms is very important for the protection and prevention of sexually transmitted infections and HIV and AIDS. Almost all of them choose contraceptives that are reversible (back) such as injections, pills, and do not use long-term contraceptive methods such as Implant or IUD because in their normal life they also want to have children and families.

Previous research by Matahari [17] revealed that commercial sex workers feel that STIs are not a serious disease because they can be cured using doctor's drugs. Their understanding is that STIs are said to be serious when they enter the AIDS phase. This shows that the concern for one's own health is still low. Based on it and existing theories, the researchers assumed that condoms were the best contraceptives that can currently be used as an initial step to prevent STIs. Using condoms will provide more security for FSW in engaging in sexual transactions than not using them at all. Moreover, FSWs who already have -risk STIs, such as having worked for a long time, are older and have many sexual partners. Nevertheless, FSW still faces considerable risks, low use of dual-method contraception, endemic intimate partner violence, and high-risk drinking with associated sexual risk-taking. In the present sample, these individual factors had greater influence on LARC use than structural factors such as a boyfriend or husband's presence, sex-work-related stigma, and violence. Structural determinants may have a greater influence on use of condoms and other user-dependent methods than on LARC use [2].

Consistent condom use previously has been found to be high $(72 \%)$, but now only $14 \%$ of the 211 women use condoms alone as a method of birth control. Nine percent reported having used injectable hormones (e.g., Depo-provera) and 1\% reported that they had used the birth control pill. FSWs' median age using any type of hormonal contraceptives (birth control pill, Depo Provera, Norplant, injectable hormones) was 33 years (IQR: 25-37). IUDs were only reported by $1 \%$ of the women interviewed. Permanent contraceptives, including tubal ligation (16.6\%) and hysterectomy $(7.1 \%)$ were more common, though primarily among older FSWs (Median = 41 years; [IQR: 36-45]). The median age among FSWs who did not use permanent contraceptives was 33.0 [IQR: 25.0-38.0]. Older age (age was measured as a continuous variable), was significantly associated with permanent contraceptive use $(p<0.001)$ [8]. Compared to hormonal contraceptives, the higher rate of condom use, particularly among younger FSWs, may reflect their knowledge of condoms' dual role in pregnancy and STI/HIV prevention. Low or no-cost condoms and their widespread availability may also contribute to the relatively higher use of condoms than other forms of contraceptives. In addition, the rate of condom use (primarily by intimate/regular partners) to be much lower than the reported rate of consistent condom use by FSWs' clients from a previous study in our setting $(72 \%)$. The low rates of condom use by intimate partners point to the need for dual protection from STIs/HIV and unwanted pregnancies. Long-lasting, female-controlled contraception methods, such as injectable hormones, may be effective in reducing unintended pregnancy [8].

Of the 201 respondents, 160 (80\%) reported that they had ever used a FP method, alone or in combination with one or more other methods. Thirteen $(6 \%)$ of these had relied on traditional methods (i.e., douching, herbal mixtures, withdrawal, or rhythm). Condoms (139/201; 69\%) and OCs (76/201; 38\%) were the most commonly reported modern methods of contraception, whereas IUDs $(5 / 201 ; 2 \%)$ and LNGECPs $(10 / 201 ; 5 \%)$ had been infrequently employed. No adolescent FSW had undergone sterilization or used an injectable, an implant, a diaphragm or a spermicide. Of women who had ever used condoms, 44\% (61/139) relied solely on this barrier method, with $16(26 \%)$ of these 61 women reporting consistent utilization of condoms with sexual partners in the past month. When asked about reasons for no condom use at last paid sex, $79 \%$ (38/48) of women responded that they were already resorting to another contraception method. Twothirds $(66 \%)$ of the girls reported they never used dual protection (condom plus another modern method) [7].

However, consistent use of condoms was low, and few practiced dual protection despite being at risk of both HIVISTIs and unwanted pregnancy. This finding has two implications: the first is the need to address the barriers to consistent condom use among adolescent FSWs; secondly, the high coverage of HIVISTI programs may represent an important entry point to reach this vulnerable population with broader SRH interventions (including prevention of unwanted pregnancy) through integrated projects [7]. Inconsistent condom use, high HIV prevalence and unintended pregnancies have also been reported among this hard-to-reach key population (Muula, 2015). In this study, though about $85 \%$ of the FSWs reported being currently using a method to delay pregnancy; many used methods with high failure rates. $91.0 \%$ reporting condom use but consistent use was $72 \%$. Inconsistent condom use is less effective as a pregnancy prevention tool and may have predisposed FSWs to unplanned pregnancies [18]. 79,774 were current contraceptive users-of those, 4548 (5.7\%) took a contraceptive as well as condoms, the study measure of dual family planning (FP) method use. Ninety-one percent $(n=4139)$ of FSWs taking dual FP methods were provided with an injectable in addition to condoms. Dual method use was lower in this study than in research studies in the region, highlighting potential differences between findings from research studies and evidence from a routine service provision setting. Self-reported consistent condom use among 
FSWs was $16.1 \%$. The findings call for further research and programs to address FSW agencies to increase dual protection against STIs/HIV and unintended pregnancy [19].

Consistent condom use is an important method of protection against both pregnancy and STIs. Multiple studies have found that consistent condom use among FSWs is low in sub-Saharan Africa: $23.5 \%$ in Swaziland (Yam, 2013) 40\% in the Democratic Republic of the Congo (Kayembe, 2008), and from 21\% consistent use with steady partners to $40 \%$ consistent use with new clients in Iringa region, Tanzania (Kerrigan, 2017). Condom use was taken from self-reports of the women attending Sauti services, using a clinical intake form completed by a health care provider. In this analysis, consistent condom use was defined as a response of "always" to the question, "Was a condom (male or female) used with permanent or regular partners or paying partners in the last 1 month?" Responses of "sometimes" and "never" were defined as inconsistent condom use. The definition of dual method use in this analysis differs from definitions in many of the research study results appearing in the literature. Because we describe a routine service delivery setting, our definition centers around service provision. Other studies use a time-bound definition of dual method use, for example, "ever used dual protection" (Erickson, 2015), "dual protection at last sex act" (Kleinschmidt, 2003 dan MacPhail, 2007), and "use of dual protection in the last 30 days" (Yam, 2013). We have defined dual method use as being provided condoms and either starting or reporting continuing a FP method during the Sauti visit.

Higher proportions of consistent condom use (with all partners, including paying and non-paying) were reported among FSWs aged 18-24 (17.1\%), single FSWs (18.8\%), FSWs with more than fve sexual partners $(15.8 \%)$, FSWs who had never been pregnant $(12.1 \%)$, and FSWs who tested positive for HIV (10.0\%). Multivariable analysis showed that FSWs aged $25-34$ years were 1.4 times $(95 \% \mathrm{Cl} 1.4-1.5)$ more likely to use a condom consistently than FSWs aged 18-24 years. FSWs who reported being single were 1.4 times (95\% Cl 1.4-1.5), and divorced/widowed were 1.5 times $(95 \% \mathrm{Cl} 1.5-1.6)$ more likely to use condoms consistently than FSWs who reported being married/ cohabiting. The likelihood of consistent condom use went up steadily with the number of partners reported. FSWs having three or four sexual partners per month were 2.8 times $(95 \% \mathrm{Cl} 2.6-2.9)$ more likely and those having five or more partners were 5.2 times $(95 \% \mathrm{Cl}$ 4.9-5.5) more likely to use condoms consistently than FSWs with one or two partners. FSWs who reported never being pregnant were 1.5 times $(95 \% \mathrm{Cl} 1.4-1.5)$ more likely to use condoms consistently than those who reported ever being pregnant. FSWs who tested positive for HIV were less likely to use condoms consistently (0.6 [95\% Cl 0.6-0.7]) compared to those who tested negative for HIV. FP Use FP use (FP method taken at the Sauti visit or self-reported continuing use) was $66.8 \%$ ( $n=79,774)$. One-third $(33.2 \%$ ) reported not using a FP method and did not take a FP method at their visit. Condoms alone were the most frequently taken FP method (31.8\% of all FSWs), followed by pills $(16.4 \%)$, injectable $(10.6 \%)$, and implants $(3.8 \%)$ (Table 1). In terms of method mix, close to half $(47.6 \%$, $n=37,947)$ of FP users took condoms alone at their service visit [19].

Self-reported consistent condom use (with all partners, paying and non-paying) (16.1\%) was also lower than in studies conducted in the region: a Swaziland study reported $23.5 \%$ consistent condom use (Yam, 2013), a Democratic Republic of the Congo study reported $40.0 \%$ [9], and a Swaziland, Togo, and Burkina Faso study showed 17.0\% (Schwartz, 2017). $20 \%$ of participants indicated they were using both condoms and a non-barrier method. For women without current pregnancy intention, access to and use of dual protection (the simultaneous use of both condoms and female-controlled modern non-barrier method) is an essential component of comprehensive reproductive health services [11], [20]. Modern non-barrier methods are the most effective for prevention of pregnancy, but do not reduce the risk of HIV acquisition. Condom use reduces the risk of HIV acquisition and thus is complementary to non-barrier methods. In the present study, it is possible that women who reported using both condoms and non-barrier methods were not using both simultaneously, and the true prevalence of dual contraceptive use may be even lower. These results indicate that interventions to improve access and use of condoms and non-barrier methods may help improve reproductive health outcomes among FSW in Zambian transit regions and other similar regions of sub-Saharan Africa [21].

\section{Age with use contraception}

From the research results, most respondents used condom contraceptives and had $18-40$ years as much as $70 \%$, more when compared to respondents who used condom contraceptives and had 41-60 years as many as $6.7 \%$. Theoretically, women over 35 years of age need safe and effective contraception because this group will experience increased morbidity and mortality if they become pregnant (Saifuddin, 2014). Recent evidence suggests that both combination pills and combination injections can be used safely by clients $>35$ years of age until menopause if there are other risks. Previous research informed that that most condom contraceptives use in older women was $22.5 \%$ and $17.5 \%$ did not use condoms, while condoms use in young women was $17.5 \%$ and $42.5 \%$ did not use condoms (Pradipta et al., 2012).

Most of sex workers in study were adults who had received a lot of information from surrounding 
environment or friends so that it influenced the contraceptive use choice. A person's age becomes a reference in terms of experience in determining the choice of contraceptive use. As one grows older, there will be a lot of learning processes that will be obtained from the journey of his life as a social and cultural being, having an important position and role for his life [22]. The study results in how most respondents use contraceptives in combination, namely condoms and injections, so the respondents themselves' awareness encourages them to behave well. Respondents stated that their customers also agreed to use condoms because they did not want to contract sexually transmitted infections or HIVIAIDS.

A woman's age can affect to suitability and acceptability of certain methods of contraception. Two groups of users Adolescents and Premenopausal Women need special attention. In general, adolescents are less likely to have media contraindications to method use (except for nulliparous adolescents who partially don't use IUDs). However, behavioral factors can be important in determining the method that will provide the best contraceptive protection [23] Older age at sexual debut was associated with increased odds of using only condoms as contraception (aOR 1.04, 95\% Cl 1.02-1.06). Still, it was not associated with using only non-barrier methods or use of both condoms and non-barrier methods. Condom availability at work was associated with increased odds of using only condoms for contraception (aOR 1.74, 95\% Cl 1.21-2.51). History of incarceration or arrest was associated with decreased odds of using both condom and non-barrier methods for contraception (aOR $0.46,95 \% \mathrm{Cl} 0.32$ $0.67)[21]$.

\section{Education with use contraception}

From research results found, the majority of respondents used condom contraceptives and entered elementary school education as much as $53.3 \%$, more than respondents who had junior high school education who used condom contraception $16.7 \%$ and respondents who had high school education who using condom contraception is as much as $6.7 \%$. Previous research showcased that between education and people's mindsets, perceptions and behavior is very significant in the sense that the higher one's education is the more rational in making various decisions (Hartanto, 2014). In relation to the use of contraceptives, education acceptors can influence the choice of contraception which indirectly affects the continuity of its use. This research is not in line with the research conducted by [24]. It was found that majority of respondents with secondary education used condom contraception as much as $72.2 \%, 27.8 \%$ in low education so education level affected the contraceptives use.

According to researcher's analysis, someone education level can support the level knowledge of
FSWs about importance things using contraceptives and low level of education is always coupled with limited information and knowledge, more higher of education level, the higher the understanding of FSWs by the information obtained and higher knowledge they have. According to Hartanto [25], the relationship between education and people's mindsets, perceptions and behavior's very significant in the sense that the more educated a person is, the more rational he is in making various decisions. In relation to contraceptives use, education acceptors can influence in terms of choosing the type of contraception which will indirectly affect the continuity of its use. More than a half $(57 \%)$ had poor knowledge of contraceptives [26]. The literature documents several individual level factors that predict consistent condom use: power to negotiate condom use (self-efficacy) [14], [15], knowledge that condom use prevents HIV infection (Adu-Oppong, 2007), having been engaged as a commercial sex worker for a shorter amount of time, and having been tested for HIV (Kayembe, 2008).

\section{Income with use contraception}

From research results, most respondents who had high incomes used condom contraceptives as much as $70 \%$, more when compared to respondents who had low incomes and used condom contraceptives as much as $6.7 \%$. In line with theory by [23], which states that with economic status, it's not a problem in using contraceptives. Because there are some contraceptives that are affordable and effective in preventing pregnancy. In addition to preventing pregnancy, the use of contraception has a general objective of providing support and strengthening acceptance of the idea of FP, that is, NKKBS which has the specific objective of reducing the significant birth rate, increasing the health and welfare of mothers and children as well as families and the nation in general, and increasing the dignity of people's lives by reducing the number birth so that population growth does not exceed the ability to increase reproduction.

According to the assumption of researchers, commercial sex workers, FSWs with high income levels will be more receptive to and follow this program and will choose an effective contraceptive method. On the other hand, a sex worker with a low income will find it very difficult to participate in FP program because in FP program, a sex worker will bear the costs herself if she uses one of contraceptives. In a study conducted by Halawa (2017) on 124 respondents revealed factors that cause women to become commercial sex workers, namely the economic need factor was obtained as much as $57.3 \%, 76.6 \%$ of the disenchantment factor, the fraud factor as much as $54.8 \%$, social status factors as much as $63.7 \%$ and media factors as much as $52.4 \%$. According to Kartono [6], the impact of commercial sex workers activities is to cause and spread venereal and 
skin diseases. The most common diseases are Syphilis and Gonorrhoe (gonorrhea), which can cause physical and spiritual disabilities in yourself and your offspring. Another result is damage to the joints of family life.

Health programming often only caters to occupational hazards, like unprotected sex with commercial clients and substance use (Wechsberg, 2006), omitting the compounding exposures sex workers might face in their domestic lives. Despite selling sex for a living, sex workers have the same needs for nurturing, motherhood, romantic partners and a "normal" domestic life as other women (Basu, 2011). Condom use with main partners is notably lower than condom use with paying clients (UCSF, 2017) and is an important counseling topic. In cases where sex workers disclosed their sex work occupation to their partners, index HIV testing will increase case finding of main partners and children for linkage to care (National Department of Health, 2016)

\section{Conclusion}

Most the respondents used condom contraception as much as $76.7 \%$, none of the respondents used injectable contraceptives, IUDs, implants, and sterility. Most of them were 18-40 years old and used condoms as much as $53.3 \%$, the majority of respondents had an elementary education and used condoms as much as $53.3 \%$, and respondents who had high incomes and used condoms were $70 \%$. Most of the FSWs in the study were adults where they had received a lot of information from their surroundings or friends at that age so that it influenced the choice of contraceptive use. The higher the level of education, the higher the understanding of FSWs with the information obtained and the higher the knowledge. High-income levels will be easier to accept, join the program, and choose an effective contraceptive method. It is hoped that FSWs can prevent STIs by using effective contraceptives and avoiding sexual intercourse without contraception.

\section{References}

1. Slabbert M, Venter F, Gay C, Roelofsen C, Lalla-Edward S, Rees $\mathrm{H}$. Sexual and reproductive health outcomes among female sex workers in Johannesburg and Pretoria, South Africa: Recommendations for public health programmes. BMC Public Health. 2017;17(Suppl 3):442. https://doi.org/10.1186/ s12889-017-4346-0

PMid:28832290

2. Ampt FH, Lim MS, Agius PA, Chersich MF, Manguro G, Gichuki CM, et al. Use of long-acting reversible contraception in a cluster-random sample of female sex workers in Kenya. Int
J Gynecol Obstet. 2019;146(2):184-91. https://doi.org/10.1002/ ijgo.12862

PMid:31090059

3. Ochako R, Okal J, Kimetu S, Askew I, Temmerman M. Female sex workers experiences of using contraceptive methods: A qualitative study in Kenya. BMC Womens Health. 2018;18(1):105. https://doi.org/10.1186/s12905-018-0601-5 PMid:29925361

4. Harnani. Qualitative study of commercial sex workers in the Jondul Region of Pekanbaru city. J Endur. 2015;3(2):302-12.

5. Ajen. Legal Policy Issues and Crime Combating Policy. Bandung: Citra Aditya Bakti; 2013.

6. Kartono K. Pathology Sosial Jilid I. Jakarta: Rajawali Pers: 2011.

7. Zhang XD, Kennedy E, Temmerman M, Li Y, Zhang WH, Luchters $S$. High rates of abortion and low levels of contraceptive use among adolescent female sex workers in Kunming, China: Across-sectional analysis. Eur J Contracept Reprod Heal Care. 2014;19(5):368-78. https://doi.org/10.3109/13625187.2014.927421 PMid:24981306

8. Duff $P$, Shoveller J, Zhang R, Alexson D, Montaner JS, Shannon K. High lifetime pregnancy and low contraceptive usage among sex workers who use drugs- an unmet reproductive health need. BMC Pregnancy Childbirth. 2011;11:61. https://doi. org/10.1186/1471-2393-11-61 PMid:21851622

9. Ashadi. Dissecting the World of Prostitution in Surabaya the Case of the Dolly Prostitution Complex. Surabaya, Yogyakarta: PT Grafiti Pres; 2016.

10. Soffiya A, Mardiyaningsih E. Gambaran Penggunaan Kontrasepsi Kondom Pada Pekerja Seks Komersial di Lokalisasi Sukosari Kecamatan Bawen Kabupaten Semarang; 2009. p. 112-9.

11. Rizali. Factors Related to the selection of injectable contraception methods in Mattoangin Village, Mariso District, Makassar city. Media Kesehat Masy Indones. 2013;9(3):176-83

12. Sarwono. Buku Acuan Nasional Pelayanan Kesehatan Materna dan Neonatal. Jakarta: YBP-SP; 2009.

13. Sugiyono, Inayah, N., Biati, L., Andriani, Z.Z.D., Nasrullah MA The social impact of closure of localization in Banyuwangi Regency: A case study on the factors that caused former CSWs to return to work in the Turian localization of Purwoharjo Banyuwangi. J Huk Islam Ekon dan Bisnis. 2015;1:1-16.

14. Satriyandari $\mathrm{Y}$, Quasimah $\mathrm{Y}$, Umrotun $\mathrm{Y}$. The Use of Contraceptives in Commercial Sex Workers in Yogyakarta. Vol. 34. AHMS 2020; 2021. p. 150-3.

15. Budiono I. Konsistensi Penggunaan Kondom oleh Wanita Pekerja Seks/Pelanggannya. J Kemas. 2011;7(2):97-101.

16. Destriani FD. A qualitative study of commercial sex workers in the Jondul area, Kota Pekan Baru in 2016. J Endurance. 2018;3(2):302-12.

17. Matahari R. Qualitative study regarding sexual perception and behavior of women commercial sex workers (CSWs) in efforts to prevent STIs in Semarang city in 2012. J Kesehat Reproduksi. 2015;3(3):113-23.

18. Bukenya JN, Wanyenze RK, Barrett G, Hall J, Makumbi F, Guwatudde D. Contraceptive use, prevalence and predictors of pregnancy planning among female sex workers in Uganda: A cross sectional study. BMC Pregnancy Childbirth. 2019;19(1):121. https://doi.org/10.1186/s12884-019-2260-4 PMid:30961542

19. Mbita G, Mwanamsangu A, Plotkin M, Casalini C, Shao A, Lija $G$, et al. Consistent condom use and dual protection among female sex workers: Surveillance findings from a largescale, community-based combination HIV prevention program 
in Tanzania. AIDS Behav. 2020;24(3):802-11. https://doi. org/10.1007/s10461-019-02642-1

PMid:31444713

20. Kemenkes RI. Family Planning Situation and Analysis. Center for Data and Information of the Indonesian Ministry of Health. Jakarta: Kemenkes RI; 2014.

21. Chanda MM, Ortblad KF, Mwale M, Chongo S, Kanchele C, Kamungoma $\mathrm{N}$, et al. Contraceptive use and unplanned pregnancy among female sex workers in Zambia. Contraception. 2017;96(3):196-202. https://doi.org/10.1016/j. contraception.2017.07.003 PMid:28711643

22. Hurlock EB. Developmental Psychology An Approach
Throughout the Life Span. Jakarta: Erlangga.; 2004.

23. Pendit. Various Contraceptive Methods. Jakarta.: EGC; 2016.

24. Fauza R, Susanti R, Mardiyaningsih E. Factors associated with the use of condoms for prevention of STDs in Wps in the Sukosari Bawen localization, Semarang Regency. Pros Semin Nas Int. 2014;2(1):165-74.

25. Hartanto. Family Planning and Contraception. Jakarta: Pustaka Sinar Harapan; 2014.

26. Twizelimana D, Muula AS. Unmet contraceptive needs among female sex workers (FSWs) in semi urban Blantyre, Malawi. Reprod Health. 2021;18(1):11. https://doi.org/10.1186/ s12978-020-01064-w

PMid:33468198 